\title{
Intention to purchase counterfeit luxury products: a comparative study between Pakistani and UK consumers
}

Hussain A, Kofinas A K, Win S

\begin{abstract}
This study aims to provide a comparison between Pakistani and the UK consumers' purchase intentions towards counterfeit luxury products by focusing on the relationships between the following factors: perceived quality, status consumption, low price and ethics. A sample of 251 university students from Pakistan (137) and the UK (114) was used. Data was analyzed using AMOS and SPSS. Results show that Pakistani consumers are satisfied with perceived quality of counterfeit products while the UK consumers are not. Status associated with the counterfeit products and prices of these products were found to be important factors for both samples. Pakistani consumers show less ethical behaviour compared to the UK consumers. Considering a single product category, i.e. luxury products, is a limitation of the study and selecting a single product category may possibly restrict the potential generalizability.
\end{abstract}

Key Words: Counterfeit products, Status consumption, Price sensitivity

\section{Introduction}

A counterfeit product is defined as an illegal replication of a legitimate product, and mimics its labeling, packaging and trademarks (Bian and Moutinho, 2011). They not only damage brands which are renowned for their excellence, but also the corresponding companies whose brands require high levels of research and development (R\&D) expenditure (Yao, 2015). Counterfeiting has existed for a significant period of time. However, while in the mid-twentieth century, only certain high-priced and high-status products such as clothes, jewellery and adornments were targeted for counterfeiting (Grossman and Shapiro, 1988). Today, countless products have been copied and imitated. They include DVDs, mobile phones, perfumes, books, cosmetics, designer luxury handbags, designer clothing, pharmaceuticals, fashion accessories and computers (Hamelin et al., 2013). Customers seem to be attracted to branded products but due to limited disposable income, counterfeit products are seen as acceptable substitutes (Cheung and Prendergast, 2006). 
Luxury products, in particular, are extremely susceptible to counterfeit manufacturers because of their high value and the perceived image of exclusivity (Phau et al., 2009). According to Carpenter and Edwards (2013), the causes for this abrupt rise in counterfeit products are: (a) accessibility of technology offering a variety of means to assemble superior value counterfeit products by replicating symbols and casings; (b) the globalization of the marketplace which makes the transportation of counterfeit products easier; (c) the manufacturing of genuine products in countries such as China, Egypt and Colombia, resulting in opportunities for the creation of counterfeits by local competitors via illegitimate channels; and (d) lack of legal penalties in a number of countries for producing counterfeits (Yoo and Lee, 2009, Castaño and Eugenia Perez, 2014).

The International Anti-Counterfeiting Coalition (2012) estimated that counterfeit products are accountable for a loss for the branded products of US\$600 billion in a single year. Yet, demand for such products is increasing at a faster pace (Hamelin et al., 2013). Many countries such as China, Singapore, France, Germany and Taiwan have legislated against production and consumption of counterfeit products, recognizing the negative effects of counterfeiting on their economies (Alcock et al., 2003). Similarly purchasing counterfeited products is considered as a civil offence and equally regarded as unlawful act in certain countries, such as the UK and the USA (Hart et al., 2004). However, the implementation of the policies domestically is often weak with loopholes in existing laws, lack of enforcement of these laws, and low rate of conviction and punishment (Vida, 2007, Budiman, 2012), implicitly encouraging manufacturers of counterfeit products to continue producing (Yao, 2005). Thus, counterfeit products have become an indirect cost to branded companies (Zhan et al., 2015).

In developing economies, consumption of counterfeits is still a new field of inquiry for marketing and consumer studies literature (Carpenter and Edwards, 2013). The majority of past studies on customer purchasing intentions towards luxury counterfeit products have been mostly carried out in developed countries (see Table 1).

Table 1 List of Studies

\begin{tabular}{|l|l|l|}
\hline Author & Title of the Study & Country \\
\hline (Nia et al. 2000) & Do counterfeits devalue the ownership of luxury brands? & Canada \\
\hline
\end{tabular}




\begin{tabular}{|l|l|l|}
\hline $\begin{array}{l}\text { (Ian, Teah and Lee, } \\
\text { 2009) }\end{array}$ & $\begin{array}{l}\text { Targeting buyers of counterfeits of luxury brands: A } \\
\text { study on attitudes of singaporean consumer }\end{array}$ & Singapore \\
\hline (Wilcox et al. 2009) & Why do consumers buy counterfeit luxury brands? & USA \\
\hline (Yoo and Lee, 2009) & Buy genuine luxury fashion products or counterfeits & South Korea \\
\hline $\begin{array}{l}\text { (Hieke,2010) } \\
\text { (Perez et al. 2010) } \\
\text { Effects of counterfeits on the image of luxury brands: An } \\
\text { empirical study from the customer perspective }\end{array}$ & $\begin{array}{l}\text { Constructing identity through the consumption of } \\
\text { counterfeit luxury goods }\end{array}$ & $\begin{array}{l}\text { Counterfeits and branded products: Effects of counterfeit } \\
\text { ownership }\end{array}$ \\
\hline $\begin{array}{l}\text { (Bian Coutinho,2011) } \\
\text { 2012) }\end{array}$ & $\begin{array}{l}\text { Love for luxury, preference for counterfeits a qualitative } \\
\text { study in counterfeit luxury consumption in China }\end{array}$ & China \\
\hline $\begin{array}{l}\text { (Kapferer and } \text { and } \\
\text { Michaut,2014) }\end{array}$ & $\begin{array}{l}\text { Luxury counterfeit purchasing: The collateral effect of } \\
\text { luxury brands' trading down policy }\end{array}$ & France \\
\hline $\begin{array}{l}\text { (Ha and Tam,2015) } \\
\text { Attitudes and purchase intention towards counterfeiting } \\
\text { luxurious fashion products in Vietnam }\end{array}$ & Vietnam \\
\hline
\end{tabular}

This study aims to develop understanding about purchase intentions towards luxury counterfeit products by examining four factors: perceived quality, status consumption, low price and ethics in the East and the West. Pakistan and the UK represent diverse populations. The former can be seen as a collectivist and developing nation and the latter as an individualistic and developed nation. Therefore, they are good representatives of diverse populations with different characteristics. Hence, they may differ considerably with respect to intentions to purchase luxury counterfeited branded products.

The factors that affect consumer buying decisions can be differentiated into direct (economic factors) and indirect (social factors), which influence the way they live and the way they consume (Babu et al., 2011). Individuals in both Eastern and Western nations seek to purchase branded luxury products to portray their social standing and individuality (Nueno and Quelch, 1998). The underlying intentions of purchasing the same luxury branded product may be different by culture (Vigneron and Johnson, 2004). Culture characterizes an individual's beliefs, behaviour and on many occasions, the way an individual acts and reacts is learned by observing or interacting with other members of the society. According to Kacen and Lee (2002) culture has a great influence on the way an individual purchases various products and services. Individuals in a collectivist society are bounded more closely by mutually establishing social practices. They also share common 
interests, norms and values (Triandis, 2001). Therefore, individuals in a collectivist society may observe themselves in a depersonalized manner where the personalities of individuals are blurred (Reid, 1987, Maines, 1989). In collectivist societies, the idea of sharing would increase the willingness of individuals to purchase counterfeits (Husted, 2000). On the other hand, individuals from an individualist society emphasize emotional independence and personal initiative (Clark and Mills, 1979), which may possibly support their need for exclusivity and strengthen their attitude towards self-expression (Franke et al., 1991).

Economic factors such as purchasing power influence or guide the buying patterns of an individual (Rani, 2014). If an individual's income and savings are higher, they will buy costly items, while on the other hand if their income and savings are low then they will buy low-priced products (Gajjar, 2013). The United Kingdom is ranked as the fifth largest economy in the world with a per capita income of almost US $\$ 44,000$ whereas Pakistan is ranks forty-fifth and per capita income is US\$1400 (Gary, 2017). The economic differences between Pakistan and the UK indicate that the intentions to purchase counterfeited luxury products will possibly vary for customers in these two countries.

Pakistan is among those countries where counterfeit products are sold openly (Ahmad et al., 2014). This attracts manufacturers due to low risk and high return. Easy availability of counterfeit products at places customers visit frequently motivates them to purchase such products (Penz and Stottinger, 2005, Chaudhry and Stumpf, 2011, Rizwan et al., 2013). In Pakistan, the absence of consumer protection laws and a non-existent enforcement of existing laws means that consumers often purchase counterfeit products even when the intention is to buy a genuine and branded product (Chaudary et al., 2014). They may sometimes fail to exercise their customer rights and buy products without examining the quality of the product in the first place (Abid and Abbasi, 2014). For instance, in Pakistan, there are over 300 brands of cooking oil. Among them, only 22 are hydrogenated vegetable oil producers (Ali and Jamal, 2011).

Although manufacturing and selling of counterfeit products are considered as criminal offences in the UK (Hopkins et al., 2003), it has not been considered as one of the main manufacturers of counterfeited products. However, it is considered as a major recipient of branded counterfeit products (Bian and Veloutsou, 2007). As previous studies suggested, one third of customers choose non-deceptive counterfeit products regardless of the potential consequences (Tom et al., 
1998, Phau et al., 2009) and 29 percent of consumers see no harm in purchasing counterfeit products if such products pose little risk and if their quality and price is good (Bian and Veloutsou, 2007). Thus, the two countries are considerably different and the differences may express themselves in terms of their motives for purchasing counterfeit products.

The main focus of this study is to identify relationships among the following factors: perceived quality, status consumption, low price and ethics in Pakistan and the UK. The underlying assumption of the study is to observe if a discernible difference for motives behind intentions to purchase luxury counterfeits is affected by the socio-cultural context of the consumers. We expect that the two populations would exhibit different attitudes along all four factors under investigation. The results will provide insights that could help the branded companies to reduce the losses which they are currently experiencing and differentiate their efforts in tackling counterfeiting in developed and developing nations. The following section establishes the importance of those factors and aims to critically evaluate and justify the inclusion of these four factors in this study.

\section{Literature Review}

Intended acquisition of counterfeits is considered as consumer misbehavior, which differs from commonly recognized norms (Lee and Workman, 2011). There are certain dimensions such as culture, social, personal and psychological, which have an influence on purchase intentions of the consumer (Ang et al., 2001, Chaudhry et al., 2005). The cultural dimension includes culture of the nation, its subcultures and the different social classes, while the social includes reference groups, roles performed in daily life, family size and status (Jacobs et al., 2001). The personal dimension includes demographic factors such as age, income, occupation and standards of living, while the psychological dynamics consist of inspiration and way of thinking (Kotler et al., 1991). Each of the four factors examined in this paper is a composite of these dimensions.

Buying intention is the disposition to purchase a specific product or service in the future (Michaelidou and Christodoulides, 2011). An individual's intention of obtaining a particular product increases as favorable attitudes and subjective norms increase (Ajzen, 1991). Purchase intention is an indicator of a person's willingness to execute a certain behavior, and it is believed to be a high priority precursor of human behavior (Wilcox et al., 2009). To achieve better satisfaction from purchasing luxuries, people often aim to maximize their status (Eastman et al., 1999). However, as expensive luxury brands become harder and more expensive for people to 
purchase they end up buying counterfeit products (Rizwan et al., 2010). Counterfeit products are purchased in place of real products with intent to deceive (Kapferer and Michaut, 2014), and research indicates that consumers neglect the negative effects of counterfeiting (Barnett, 2005, Perez et al., 2010). An influential aspect on purchase intention of counterfeit products is the degree of control over the behavior, i.e. to what extent the potential shopper has an ability to suppress their desires (Phau et al., 2009). While purchasing counterfeit products, in many cases buyers fail to control their desires (Bian et al., 2015). Luxury goods are high priced and are accepted and adored by others; as a result, individuals might be keen to purchase luxury counterfeit goods mostly with the intention of achieving the symbolic benefits associated with the product (Cheek and Easterling, 2008). Consequently, demand for inexpensive counterfeit products is increasing around the world as these products can provide fulfillment comparable to a luxury genuine product at a much lower price (Juggessur, 2009). Spotting counterfeits is difficult for brand designers as counterfeited products look similar to the branded products (Perez et al., 2010), the only possible differentiation being the quality of the two products (Eisend and Schuchert, 2006).

Deceptive and non-deceptive counterfeit purchase are two different types of counterfeiting behavior (Grossman and Shapiro, 1988, Matos et al., 2007). The former would be when customers are engaged in buying a fake product without being conscious of the violation of intellectual property, i.e. they did not intend to violate the intellectual property rights of the brand the counterfeit imitates (Matos et al., 2007, Staake et al., 2012). Conversely, non-deceptive counterfeit purchase is when customers are aware they are acquiring a fake product (Eisend and Schuchert, 2006). Reduction in sales as a result of such non-deceptive counterfeit purchase traditionally was not considered as important, because these customers never had the intention (or ability) to buy the genuine product at first place (Chuchinprakarn, 2003). Studies suggest that possibly one third of all customers who purchase a counterfeit have done so knowingly, despite the fact that the act is a crime (Phau et al., 2009). According to International Anti-Counterfeiting Coalition (2012) estimates, branded products lose an approximate US\$200 billion as the result of such nondeceptive counterfeit purchases, with both demand and supply sides of the transaction willingly breaking the law. This phenomenon warrants further investigation as the assumption that it is not as damaging as branded companies assume may be a myopic way of viewing this phenomenon. This research turns to the existing literature to explore the factors that might have an effect on 
purchase intentions. The first factor that is prominent in the literature is the ethical dimension, which is examined in the next subsection.

\subsection{Perceived Quality}

Perceived quality is an individual's judgment of a product's ability to satisfy expectations and demonstrate its superiority when compared to substitutes (Hilton et al., 2004). Often perceived quality is an emotion regarding a particular product and its intangible qualities (Cheung and Prendergast, 2006). Perceived quality may be linked to the actual quality of the product and can be based on the current perception or customer experience with the product; it is a customer-centric concept and a fundamental aspect of purchasing behaviour (Zeithaml et al., 1996). On the other hand, perceived quality of a product may be linked to other variables of marketing such as product involvement, consumer satisfaction and purchase intentions (Jang and Namkung, 2009). Previously, perceived quality and customer satisfaction were considered similar and were used interchangeably (Penz et al., 2008). However, Wee et al. (1995) advocated that buyer satisfaction and perceived quality of the product are distinct in two ways, i.e. perceived quality of product and service is specifically used for features and can be distinct from purchasing experience, whereas satisfaction is the outcome of any facet and it is a pre- and post-purchase concept (Eisend and Schuchert, 2006). Satisfaction cannot be ensured by the company while perceived quality can be controlled by the company to an extent (Hieke, 2010).

Perceived quality is taken as a post-purchase factor (Bloch et al., 1993) and is based on the underlying dimensions and characteristics of the product such as reliability and performance; these dimensions tend to be quite universal (Bian and Moutinho, 2011). The main problem with counterfeits is that not only do they look similar to the original products and have the same logos, but increasingly they have the same level of perceived quality, i.e. they are nearly identical to the genuine article (Matos et al., 2007). In other cases, even if the perceived quality is lower, the main benefits of purchasing a counterfeit product are still realized and thus customers may still voluntarily purchase them (Vida, 2007). Interestingly individuals who are purchasing counterfeit products do not consider counterfeits inferior to the genuine products in terms of quality (Chaudhry and Stumpf, 2011). Thus, besides the loss of revenue, counterfeiting results in additional losses in reputation, customer confidence, and good will for the branded product (Gentry et al., 2006). A counterfeit product contains prestige utility provided that its quality meets at least an acceptable 
level (Grossman and Shapiro, 1988). The healthier the expected performance is, the more it is expected that individuals will buy counterfeits leading to the following hypothesis.

$\mathrm{H}_{1}$ : Perceived quality of counterfeit products positively affects an individual's purchase.

\subsection{Ethics}

Consumer ethics deals with an individual's decision, intentions and perception of consumption, and how these factors lead to either acceptance and recognition or rejection and ejection from society (Ha and Lennon, 2006). Every individual may hold distinct ethical beliefs, which affect their purchase intentions (Vitell, 2003). To measure the difference in ethical beliefs among individuals, Forsyth (1980) identified two dimensions, i.e. idealism and relativism. Relativists do not follow established norms and ethical values and their decisions are made dependent on the moral context of a particular situation (Forsyth, 1980). On the other hand, idealists adopt an absolute morality, regardless of the context; i.e. what is ethically or morally right is right in every situation and what is wrong ethically or morally is wrong in every situation (Forsyth, 1980, Shang et al., 2008). Even so, the two dimensions are not mutually exclusive (Shang et al., 2008), idealist consumers may be less likely to accept a counterfeit purchase, whereas ethically relativist consumers may be more likely to justify their involvement with counterfeit products by envisioning the positive outcomes (Alfadl et al., 2014). Islamic scholars have discussed the moral and ethical values that should be considered in daily transactions (Ali, 2011). According to the Islamic point of view, ethics has a similar meaning to aklaq and it can be defined as a trait of an individual's soul, which will make an individual act naturally without any consideration (Ali and Al-Aali, 2015). Whenever individuals meet a moral dilemma and are required to take a decision, they experience three phases: realizing the moral problem, developing an ethical opinion about it and devising action plans to deal with the problem at hand (Ha and Lennon, 2006). The individual's stance, whether idealist or relativist, would have a significant impact in shaping their ethical decisions, as ethical concerns related to what is right and what is wrong play a vital role in buying behavior (Li and Seaton, 2015).

Consumer ethics are the values and standards which direct individual or group actions to attain and utilize products and services (Sagar et al., 2011). Early studies of marketing ethics paid attention to principled approaches within specific fields, e.g. sales, marketing research, advertising and social marketing and lacked focus on the buyer side (Gino et al., 2010). However, ethics in 
consumer behavior has gained greater importance in research, particularly when it comes to the purchase of counterfeit products (Eisend and Schuchert, 2006). Those customers who give more value to honesty and responsibility are expected to hold negative attitude towards counterfeit products (Maldonado, 2005). When Wilcox et al. (2009) examined the effect of ethical judgment and buying intentions towards counterfeit products, they found that those who believed that purchase of counterfeits was ethically unjustifiable were less likely to buy counterfeit products (Vitell, 2003). Another study showed that some consumers defended their purchasing of counterfeits by describing their behavior as less unethical than that of the seller (Phau et al., 2009) an ethical relativist justification. In general, individuals with high capability to justify their unusual behavior have shown an extra keenness to acquire fake products, especially fashion products (Vida, 2007). Therefore, it is expected that ethical concerns would influence individuals' purchase intentions towards counterfeit products. This leads to the following hypothesis.

$\mathrm{H}_{2}$ : Ethical concerns positively affect an individual's intentions to purchase counterfeit products.

\subsection{Status Consumption}

Status is an indicator of one's position in society especially when compared to other individuals in that society (Eastman and Eastman, 2011). Status may be indicated in economic terms (Kempen, 2003), and thus the propensity and ability of an individual to acquire the ownership of prestigious products and services indicates their status in society (Nia et al., 2000). The consumption of products that indicate status is influenced by the degree to which an individual seeks status (Eastman and Eastman, 2011). One of the characteristics of a brand is that it has a particular status associated with it, and thus the possession of signifiers of that brand (products, images, service, attitudes) bestows to the individual membership to a specific social group and an associated set of images (Van Kempen, 2003, Ian et al., 2009). The status associated with a particular product can be unbundled in counterfeit products from other factors such as perceived quality even if the two features may be interlinked in the original product (Perez et al., 2010); for example, in the case of a counterfeit Rolex, the consumer has to give up some of the functional aspects of the product while maintaining the status associated with the brand (Rutter and Bryce, 2008).

Usually people purchase counterfeit brands because they want to show off their wealth and convey the message that they can afford the expense of renowned goods (Yoo and Lee, 2009); or to indicate that they are part of a particular social class (Ergin, 2010). Counterfeited luxury products 
allow consumers to convey ownership of the associated status (Chaudhuri and Majumdar, 2006). Such status-seeking consumers will obtain products which have noticeable logos in order to display their status and wealth (Ha and Tam, 2015), while consumers seeking uniqueness in a product will acquire luxury brands, and may pay more money for an unseen label (Babin and Babin, 2001). For both consumer types, even though they will purchase luxury items for different motives, their fundamental motive of self-image enrichment is similar (Chaudhry and Stumpf, 2011). According to Park et al. (2008), an individual's awareness of status may encourage them towards luxury brands as these products symbolize wealth and social status. Therefore we hypothesize that:

$\mathbf{H}_{3}$ : Perceived status positively affect an individual's intentions to purchase counterfeited.

\subsection{Low Price}

According to Bloch et al. (1993), the lower price of counterfeit products is the main advantage over branded products. Luxury products are expensive because they are recognized and respected by everyone, thus most consumers buy them to convey emblematic meaning (Ian et al., 2009). The amount of saving on the counterfeits can make consumers neglect the compromised product quality and the ethical dilemmas the purchase may entail (Norum and Cuno, 2011). Consequently, the purchase intention towards counterfeits is heavily affected by low price, and price is the main strategy used to catch the attention of consumers (Ang et al., 2001, Penz et al., 2008, Chaudhry and Stumpf, 2011). Thus price sensitivity is expected to be the most important factor for individuals (Prendergast et al., 2002) wanting to impress others (Ha and Lennon, 2006, Furnham and Valgeirsson, 2007). Moreover individuals' intentions to buy genuine brands will also be affected by price sensitivity, as confirmed by Huang et al. (2004) where individuals with higher price sensitivity exhibited an opportunistic behavior towards counterfeits. Because of low price, individuals will exhibit greater purchase intentions if their income is lower. Thus, based on the average income in each country the following hypothesis arises:

$\mathbf{H}_{4}$ : Low price positively affect an individual's intentions to purchase counterfeited products.

\subsection{Conceptual Framework}

The conceptual model developed starts with the selection of variables which could potentially increase a consumer's buying intentions for counterfeit products, and aims to clarify how those 
variables may relate to each other. Earlier research has clearly shown that product price positively correlates with the counterfeited products (Penz et al., 2009).

Figure 1: Conceptual Framework.

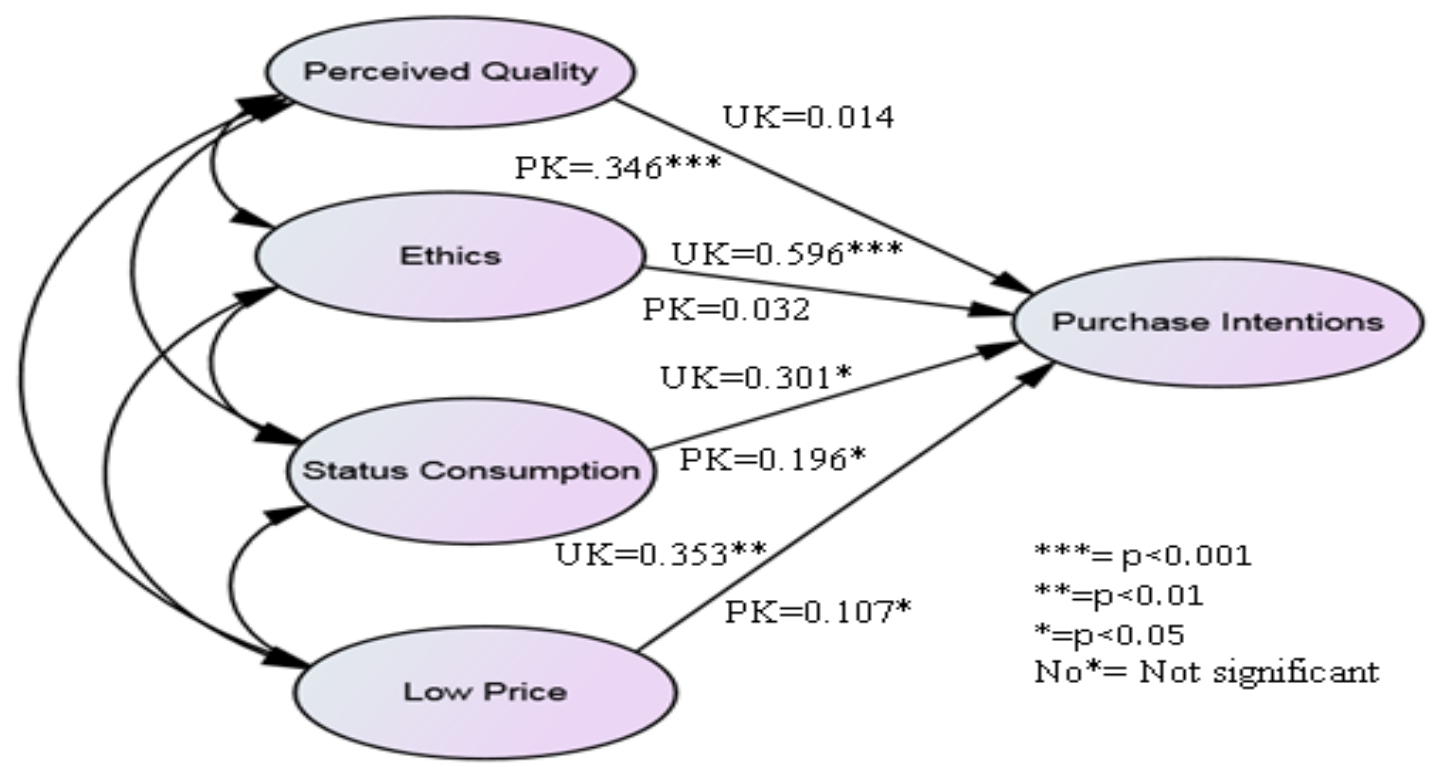

The two populations considered in this study were postgraduate student populations, one based in Pakistan and one based in the UK. The following section explores the methodology used to compare the two populations with regards to purchase intention.

\section{Research Methodology}

\subsection{Sample and Data Collection}

The data was collected from two culturally diverse countries, i.e. Pakistan and the UK, by using self-administered survey questionnaires. Data was collected from universities in both countries located in Islamabad, Luton and London. The researcher obtained 137 completed questionnaires from Pakistani respondents and 114 questionnaires from UK respondents, a total sample of 251 respondents. In addition, the respondents were also asked to provide demographic information such as gender, age and education. Responses were analyzed by using Structural Equation Modeling (SEM). It has been recommended for used with a minimum 100-200 sample size (Boomsma, 1985), or 10 cases per variable (Nunnally, 1978). Similarly, Wolf et al. (2013) conducted an SEM study with a sample size of 200. Other researchers have suggested that a study 
where the research would use SEM with a sample size of 200, or with 5 to 10 cases per variable would be sufficient (Weston and Gore, 2006, Kline, 2010). The questionnaires included structured close-ended questions and consisted of multi-item scales and demographic questions. A Likert scale of 1 to 5 is utilized to document respondents' reactions (1=strongly disagree/ disagree/ neutral/ agree/ 5=strongly agree).

\subsection{Findings and Discussion}

\subsubsection{Descriptive Results}

Table 2 summarizes the sample's profile and characteristics. The two groups consist of predominantly adult (26-30 years old) students. Pakistani respondents were mostly men (54.7\%), doing postgraduate degrees (78\%). The majority of them have been involved in purchasing a counterfeit product knowingly (80.3\%) and most of them have purchased up to three counterfeit products (53.3\%). Most of the Pakistani respondents (66.4\%) thought it is ethical to purchase counterfeit products. The most purchased product category among Pakistani respondents was apparel products (59.1\%), followed by designer hand bags (25.5\%), while only 15.3\% were involved in the purchase of counterfeited accessories. In contrast, the UK respondents were more balanced (female students: 50.8\%), and most of them doing a postgraduate degree (68.3\%). The majority of the consumers from the UK (76.7\%) have never been involved in the purchase of a counterfeit, and only $19.2 \%$ of the respondents have purchased counterfeit products up to three times. A very small proportion of the respondents have ever purchased counterfeit products knowingly (23.3\%) and the majority of the UK respondents (80\%) think buying counterfeit products is unethical. However, they have also been involved in the purchase of counterfeit products and the most purchased product category among the UK respondents was apparel products (57.5\%); designer hand bags appeared as the second most favorite category (34.2\%), while a small number of individuals (8.3\%) have been involved in the purchase of counterfeit accessories. The gender difference in the two populations is mainly because in Pakistan, male enrollment is higher in university at both undergraduate and postgraduate levels.

This gender difference in the populations leads to an interesting insight about the Pakistani and UK respondents, as most of the Pakistani male respondents ( $n=62$ out of 75 ) mentioned that they purchase counterfeit branded clothes such as shirts and t-shirts, and the second most purchased category ( $\mathrm{n}=10$ out of 75 ) is counterfeited accessories, such as ties and belts. However, the majority 
of the male respondents ( $n=48$ out of 59) from the UK declared that they mostly purchase counterfeit clothes; the second most purchased category among the UK male respondents is clothes, such as shirts and t-shirts. Whereas the majority of Pakistani female consumers have more interest in designer handbags ( $n=38$ out of 62 ), the majority of the UK female respondents $(n=33$ out of 61) mentioned that they purchase counterfeit accessories clothes.

Table 2: Descriptive Statistics

\begin{tabular}{lll}
\hline Demographics & British Sample & Pakistani Sample \\
\hline Gender & & \\
Male & $49.2 \%$ & $54.7 \%$ \\
Female & $50.8 \%$ & $45.3 \%$ \\
Total & 100.0 & 100.0 \\
Age & & \\
$20-25$ & $37.5 \%$ & $27 \%$ \\
$26-30$ & $40.8 \%$ & $48.2 \%$ \\
$31-40$ & $21.7 \%$ & $24.8 \%$ \\
Total & 100.0 & 100.0
\end{tabular}

\section{Education Level}

$\begin{array}{lll}\text { Undergraduate } & 31.7 \% & 21.2 \% \\ \text { Postgraduate } & 68.3 \% & 78.8 \% \\ \text { Total } & 100.0 & 100.0\end{array}$

Knowingly Purchased Counterfeit products

$\begin{array}{lll}\text { Yes } & 23.3 \% & 80.3 \% \\ \text { No } & 76.7 \% & 19.7 \% \\ \text { Total } & 100.0 & 100.0\end{array}$

How many time

$\begin{array}{lll}\text { Never } & 76.7 \% & 9.5 \% \\ 1-3 & 19.2 \% & 53.3 \% \\ 4-6 & 2.5 \% & 22.6 \% \\ 7-9 & 1.7 \% & 14.6 \% \\ \text { Total } & 100.0 & 100.0\end{array}$

Product Category Purchased

$\begin{array}{lll}\text { Designer Bags } & 34.2 \% & 25.5 \% \\ \text { Accessories } & 8.3 \% & 15.3 \% \\ \text { Apparel Products } & 57.5 \% & 59.1 \% \\ \text { Total } & 100.0 & 100.0\end{array}$

\section{Buying Counterfeit Products}

Ethical 20.0\%

$66.4 \%$ 


$\begin{array}{lll}\text { Unethical } & 80.0 \% & 33.6 \% \\ \text { Total } & 100.0 & 100.0\end{array}$

\subsubsection{Scale Reliability and Factor Analysis}

The measurement model is used to explain relationship between observed and latent variables; the structure model evaluates the relationship between latent variables. The measurement model is first evaluated by examining the reliability of each individual item, the construct reliability and then the validity of all the constructs, in order to make sure that the construct's measures are reliable and valid before evaluating the nature of the relationships between the constructs (Lau and Roopnarain, 2014). By using the measurement model reliability of each individual item assessed, adequate reliability occurs when factor loading of every item is greater than .06 (Nunnally and Bernstein, 1994); however, it has been highlighted that factor loading values above 0.60 are considered reasonable and values above 0.80 can be considered as good. Similarly, for the reliability of items, confirmatory factor analysis was conducted as shown in Table 3. While analyzing reliability of individual items in our study, no item was deleted. As mentioned by Hair et al. (2011), if an indicator's loading is between 0.40 and 0.70 , it should be considered for removal from the scale, only if removing an item results in an increase in composite reliability. However, indicators with low loadings, i.e. below 0.40 should always be removed from the scale because such indicators have less explanatory power for the observed variables on latent variables. Therefore, to ensure the instrument's reliability and validity a pilot study was carried out with a small sample of 30 students. During this pilot study, some of the items with poor loadings were excluded from the questionnaire to ensure internal consistency between items and to obtain a reasonable average (above 0.65 ) of Cronbach's alpha and thus ensure higher reliability values for the instrument used. Item loadings for each factor were above 0.50 and composite reliability was above 0.7, which is considered an ideal composite reliability score (Vandenbosch and Higgins, 1996), while alpha values were above 0.7. According to Devellis (2003), the value of Cronbach's alpha should be greater than 0.6, while Carmins and Zeller (1979) recommend that the value should be 0.80 in order to establish internal consistency. However, Nunnally (1978) proposed a rule of thumb where the acceptance levels of alpha should be higher than 0.70 . Thus, an alpha value 0.70 was used as a measure to determine the internal consistency of the scale used for the study.

Validity of constructs was established by confirming consistency among the measurement items; to achieve this pilot test of the instrument was carried out. As suggested by Churchill (1979), a 
construct's convergent and discriminant validities have to be examined. Therefore, for this study the researchers measured the convergent validity of the constructs by checking composite reliability (CR). The values of CR for the five constructs were between .72 and .88 (Table 3), all more than the recommended minimum value 0.70 (Hair et al., 2009).

Table 3: Confirmatory Factor Loadings, Composite Reliability and Cronbach’s Alpha

\begin{tabular}{|c|c|c|c|c|c|c|}
\hline & $\begin{array}{l}\text { Estimate } \\
\text { Data }\end{array}$ & Pak & $\begin{array}{l}\text { Estimate } \\
\text { Data }\end{array}$ & UK & $\begin{array}{l}\text { Cronbach's } \\
\text { Alphas }\end{array}$ & $\begin{array}{l}\text { Composite } \\
\text { Reliability (CR) }\end{array}$ \\
\hline PQ4 & 0.739 & & 0.797 & & $0.823 \mathrm{PK}$ & $0.823 \mathrm{PK}$ \\
\hline PQ3 & 0.749 & & 0.825 & & & \\
\hline PQ2 & 0.688 & & 0.637 & & & \\
\hline PQ1 & 0.753 & & 0.638 & & $0.817_{\mathrm{UK}}$ & $0.818 \mathrm{UK}$ \\
\hline ETH4 & 0.579 & & 0.766 & & $0.768_{\mathrm{PK}}$ & $0.772_{\mathrm{PK}}$ \\
\hline ЕTH3 & 0.714 & & 0.732 & & & \\
\hline ETH2 & 0.736 & & 0.748 & & & \\
\hline ETH1 & 0.675 & & 0.792 & & $0.827_{\mathrm{UK}}$ & $0.829_{\mathrm{UK}}$ \\
\hline SC4 & 0.837 & & 0.603 & & $0.881_{\mathrm{PK}}$ & $0.881_{\mathrm{PK}}$ \\
\hline SC3 & 0.819 & & 0.731 & & & \\
\hline SC2 & 0.816 & & 0.813 & & & \\
\hline SC1 & 0.813 & & 0.560 & & $0.724_{\mathrm{UK}}$ & $0.725 \mathrm{UK}$ \\
\hline PS4 & 0.823 & & 0.690 & & $0.884_{\mathrm{PK}}$ & $0.885 \mathrm{PK}$ \\
\hline PS3 & 0.795 & & 0.890 & & & \\
\hline PS2 & 0.823 & & 0.812 & & & \\
\hline PS1 & 0.837 & & 0.701 & & $0.816 \mathrm{UK}$ & $0.819 \mathrm{UK}$ \\
\hline PI2 & 0.604 & & 0.742 & & $0.818_{\mathrm{PK}}$ & $0.82_{\mathrm{PK}}$ \\
\hline PI3 & 0.744 & & 0.513 & & & \\
\hline PI4 & 0.805 & & 0.738 & & & \\
\hline \multirow[t]{2}{*}{ PI5 } & 0.758 & & 0.784 & & $0.784_{\mathrm{UK}}$ & $0.792_{\mathrm{UK}}$ \\
\hline & & & & & & $\begin{array}{l}* * *=p<0.001 \\
* *=p<0.01 \\
*=p<0.05\end{array}$ \\
\hline
\end{tabular}




\subsubsection{Structure Model Assessment}

The results of the path analysis of the structure model confirm a reasonable goodness of fit index for both samples. Therefore, the hypothesized relationship between the latent variables and their related observed variables was assessed and the relationships between the independent and the dependent variables were modeled. The results related to goodness of fit evaluation indicated decent fit for the structural model. The chi-square test results were decent while other indicators showed decent fit for the model; the values of (RMSEA) and (CFI) in Table 4 are show that the model is fit for analysis. According to $\mathrm{Hu}$ and Bentler (1999), the CFI value should be greater than 0.90 in order to ensure model fitness. In our model, the value of CFI is 0.948 and 0.937 for the Pakistani and UK samples, respectively, which are acceptable values. The value of RMSEA tells how well the model is fit for analysis, during the early 1990s, the RMSEA range was between 0.05 and 0.10 and values below 0.05 were considered as good fit value and above 0.10 as a sign of poor fit. According to Browne et al. (1993), the values of RMSEA should be less than 0.08 and ideally, less than 0.05. In our model, the values for both the samples, i.e. Pakistani and UK, of RMSEA are .054 and .058, respectively; this shows that the model is fit for testing hypotheses.

Table 4 Structure Model Assessment

\begin{tabular}{lllll}
\hline & Pakistani Sample & British Sample \\
\hline Model Fit Indices & & & & \\
Chi-square & 223.855 & & 223.364 & \\
Degree of Freedom & 160 & & 160 & \\
Probability Level & 0.001 & & 0.001 & \\
CFI & 0.948 & & 0.937 & \\
RMSEA & 0.054 & & 0.058 & \\
Hypnotized Relationships & Estimate & P Values & Estimate & Palues \\
& & & & \\
$\mathrm{H}_{1} \quad \mathrm{PQ} \rightarrow \mathrm{INT}$ & $.346^{* * *}$ & .001 & 0.014 & .879 \\
$\mathrm{H}_{2} \quad \mathrm{ETH} \rightarrow \mathrm{INT}$ & 0.032 & .730 & $0.596^{* * *}$ & .0001 \\
$\mathrm{H}_{3} \quad \mathrm{SC} \rightarrow \mathrm{INT}$ & $0.196^{*}$ & .016 & $0.301^{*}$ & .044 \\
$\mathrm{H}_{4} \quad \mathrm{PS} \rightarrow \mathrm{INT}$ & $0.107^{*}$ & .050 & $0.353^{* *}$ & .002 \\
\hline
\end{tabular}

\subsubsection{Hypothesis Testing}

For hypothesis testing confirmatory analysis was used 
$\boldsymbol{H}_{1}$ : Perceived quality of counterfeit products positively affects an individual's purchase intentions. The difference in perceived quality is statistically significant in the Pakistani sample; results show a strong support in the relationship of perceived quality and purchase intention towards counterfeit products $(\beta=0.346, \mathrm{p}<0.001)$, and that is a strong and positive correlation to purchase intention. The results are different from the results of previous studies (Huang et al., 2004, Ian et al., 2009), which found negative effect of quality on intentions to obtain counterfeit luxury products and suggested that the low-priced counterfeit products would be perceived to have a lower quality. However, in the UK sample, perceived quality is not shown to be significant predictor of purchase intentions ( $\beta=0.014, \mathrm{p}>0.0001$ ); hence, for the UK sample the hypothesis is rejected. Our results are similar to Penz et al. (2008) results, who stated that individuals who purchase counterfeit products believe that these products are as good as the original products.

This result indicates that Pakistani consumers are not interested in the quality aspects of counterfeit products and will purchase counterfeit products if they can afford to purchase them. While having complete knowledge about counterfeit and original products they are willing to purchase counterfeit products; that means quality of counterfeit products does not have any impact on their buying intentions. On the other hand, the UK consumers consider product quality before making a purchase; therefore, they would not be attracted towards counterfeit products because of low perceived quality.

$\mathrm{H}_{2}$ : Ethical concerns positively affect an individual's intentions to purchase counterfeit products. In the Pakistani sample no support has been found for a causal relationship between ethical behaviour and counterfeit purchase intentions; thus the hypothesis is rejected, i.e. $\mathrm{H}_{2}(\beta=0.032$, p>.001). Thus the less ethical behaviour they show, the more they will be inclined towards counterfeit purchase and vice versa. This indicates that individuals from Pakistan ignore ethical considerations, and individuals fail to see any ethical issues arising from the purchase of counterfeit products. Even when customers know that purchasing counterfeit products is cheating both the genuine producers and the customers themselves, they still purchase the product. This finding contradicts the results of earlier researchers such as Chaudhry and Stumpf (2011) and Phau et al. (2009), who indicate that the higher the level of ethics, the less the consumer is expected to be involved in counterfeit acquisition. However, results from the UK sample are in accord with these studies and ethical consideration has a positively and significantly correlation with purchase intentions $(\beta=.596, \mathrm{p}<.001)$. This means the more individuals show ethical behavior, the less they 
will show purchase intentions towards counterfeit products; and it also indicates that consumers in the UK are aware about the ethical issues. Therefore, large majorities do not engage in unethical purchasing and consider purchasing counterfeit products as unethical, violating copyrights and intellectual property rights.

Though Pakistani respondents have a similar educational background and fall into same age group, there is clearly a difference in their understanding of the ethical dimension in purchasing counterfeit products. That could be due to absence of laws (or implementation of said laws) against selling of such products and lack of education or customer awareness with regards to copyright issues.

Нз: Perceived status positively affect an individual's intentions to purchase counterfeited products. In the Pakistani sample, a significant association has been found when perceived status was regressed against purchase intentions. The results confirm the link between perceived status and intention to purchase counterfeit products $(\beta=0.196, \mathrm{p}<0.05)$. Similarly, in the UK sample, a significant relationship has been found between status associated with a brand and purchase intentions $(\beta=0.301, \mathrm{p}<0.05)$. Thus if the brand is famous and a higher status is associated with it, then purchase intentions for both samples will increase further. Results are in accordance with previous studies; for example Phau et al. (2009) found a positive effect between status associated with these products and purchase intentions towards counterfeit products. Due to the high prices of luxury fashion products only high-status consumers can afford to purchase them (Ha and Tam, 2015). Therefore, individuals who wish to achieve a higher status are attracted by counterfeit luxury products. As a result, status consumption produces a positive purchase intention towards counterfeit products. However, Chaudary et al. (2014) found an insignificant relationship between counterfeit shoes and status consumptions, indicating that the type of product may play an important role when it comes to the purchase of counterfeit products, an assertion further supported by Chaudhry and Stumpf (2011). These results indicate that both the Pakistani and the UK consumers are status-orientated and the purchase of counterfeit products enhances customers' status within their social circle.

H4: Low price positively affect an individual's intentions to purchase counterfeited products. Regarding the low price of counterfeit products, results revealed that it significantly affects purchase intention of both the UK $(\beta=0.353, \mathrm{p}<0.01)$ as well the Pakistani consumers $(\beta=0.107$, 
$\mathrm{p}<0.05)$. Therefore, the hypothesis is accepted for both populations; these results are similar to Staake et al. (2009), who found that low-priced counterfeit products motivate individuals to purchase such products. Similarly, a study conducted by Chuchinprakarn (2003) found that those consumers who cannot afford to purchase high-priced branded products consider low-priced counterfeit products as an adequate substitute for these products. As the sample for this study is university students, financially most of them cannot afford to purchase branded products, therefore they would purchase counterfeited branded products. The respondents of our study have purchased counterfeit products while considering price as the most vital contributing factor. When counterfeited products are available at a relatively low price then customers prefer to buy these products (Bloch et al., 1993). This links with $\mathrm{H}_{3}$ as the low price of the product becomes a shortcut to status enhancing purchases. It would be interesting in a future study to evaluate the level to which price mediates the impact of perceived status has on intended purchasing behaviour.

\section{Discussion}

Existence of counterfeit products in both developing and developed countries is an indication of the success of counterfeit brands. It has been noticed that only well-known brands that are liked and recognized are targets for counterfeiting. Hence, it could be argued that famous brands pay the price because of the high levels of recognition by the majority of buyers.

The results of this study should cause disquiet. This research has revealed that majority of Pakistani respondents have been involved in the purchase of counterfeit products, with $80.3 \%$ of the respondents knowingly purchasing counterfeit products. A large number of the respondents have purchased up to three counterfeit products knowingly. It was not expected that in a country with a devout Muslim majority so many individuals would purchase counterfeit products (Mujtaba et al., 2012). In Islam, ethical guiding principles and practices are identified and approved (Riquelme et al., 2012). In fact, during the early centuries of Islam, Muslim scholars and rulers emphasized ethical conduct specifically when dealing with others (trade) (Wani, 2013), and fear of Allah and obligation to the welfare of society were the hallmark of the time (Ahmad, 2009) - and this should be the case in Muslim countries such as Pakistan. Results were contradictory to expectation with $66.4 \%$ of the respondents replying that buying counterfeit products was ethical. On the other hand, the UK respondents exhibited little attraction towards counterfeit products, as only $23.3 \%$ of the respondents have knowingly purchased counterfeited products. A large number (76.7\%) of 
respondents from the UK sample have never purchased counterfeit products. When responding to the statement "purchasing counterfeit products is ethical or unethical" the majority of the UK respondents (80\%) considered it unethical. According to Dubinsky et al. (2005), ethically relativist consumers are expected to show less concern towards ethically dubious situations, whereas the ethically idealist individuals show the reverse. The results show that Pakistani consumers tend to be ethically relativist and conversely, the UK respondents tend to be ethically idealist.

Results have also revealed some commonalities among respondents from both countries. When it comes to purchasing counterfeit products, they prefer to purchase apparel products (UK sample 57.5\%, Pakistani sample 56.2\%). Designer handbags were another category that has been purchased frequently by the sample from both countries (UK sample 34.2\%, Pakistani sample 25.5\%). More importantly, when examining status and low price, both samples exhibited strong correlation. For individuals from both countries, purchasing counterfeit products becomes a cheaper alternative, confirming the results from Furnham and Valgeirsson (2007) that the number of counterfeit purchases increases with decrease in price. In both countries, consumers buy lavish counterfeited products to establish themselves distinctively and express their status to others in society and to enhance their social status. As Cheung and Prendergast (2006) stated, individuals make use of these brands for getting recognition in society. Similarly, Phau et al. (2009) also found that status consumption has a positive impact on purchase intentions towards counterfeit products. While purchasing counterfeited products, consumers seem to be aware of the compromises they have made. Consumers appreciate that genuine products will have a higher price and counterfeit products will have a lower price and possibly lower quality; this fact may discourage individuals to show intentions to purchase counterfeit products (Ha and Tam, 2015). However, with developments in technology it has become very difficult to differentiate between original and counterfeit products. Individuals have a different opinion about counterfeit products: Pakistani consumers have high expectations towards the quality of counterfeits, while UK respondents have expressed a different view about the quality of these products and results indicate that they perceive these products as not as good as the original brands. Perceived quality of counterfeit products appeared as an important factor for Pakistani respondents, indicating that they wish to achieve both internal satisfaction and outer appearance and therefore, they purchase counterfeit products with materialistic value. In Pakistan the economic condition of the country with low purchasing power and high inflation rates encourages individuals to purchase such products (Ahmad et al., 2014). 
Because of high inflation (Kemal, 2006), students get a limited amount of money from their parents as pocket money; therefore they may attempt to purchase counterfeit products. Most of the individuals in the Pakistani sample mention that they intentionally purchase counterfeit products just to show off. On the other hand, the majority of the UK consumers have not purchased counterfeited products intentionally, but still some of them have been involved in the purchase of counterfeit products. They showed less interest towards the purchase of counterfeit products and in UK society, counterfeit products are not acceptable. Therefore, from fear of losing social respect individuals restrict themselves from such purchases (Perez et al., 2010). Another reason behind Pakistani consumers being more attracted towards counterfeit products may be easy access to counterfeit products. One can purchase these products without any fear because of the absence of laws in the country. Awareness is also a reason that separates the two cultures: in Pakistan lack of awareness about purchase of counterfeit product and related consequences is another reason, due to which most of the respondents have been involved in the purchase of counterfeit products. Whereas in the UK the situation is different, as they are aware about consequences related to the purchase of counterfeit products; they are aware that due to this they will lose social respect and acceptance (Bian and Veloutsou, 2007).

\subsection{Conclusion}

This study provides an insight into consumers' purchase intentions towards counterfeit products in Pakistan and the UK. In today's competitive environment, marketers are required to obtain a better knowledge about buying intentions of individuals. Manufacturers of branded products have been focusing on developing new technologies to make counterfeiting difficult, but these actions are only relevant to business and ignore the demand side. Measures have to be taken to restrain the demand side, as well as discouraging customers from buying counterfeit products. In order to devise action against counterfeit consumption it is important to understand the specific reasons why individuals obtain counterfeit products. Producers of luxury brands should involve themselves directly in disparaging counterfeit products. Introducing new laws, especially in developing economies by targeting consumers, could establish negative social norms against counterfeit purchase. Alternatively, luxury brands could use status as a promotional theme in favor of the genuine product indicating that purchasing counterfeits or getting caught using counterfeits means that individual shoppers have not achieve the desired status. Previously, it was price of counterfeit products that was considered as the most influential factor, but this study has revealed that for the 
Pakistani sample, quality of the counterfeit products and status associated with them also affects their purchase intentions towards counterfeit products. It is hard to determine whether this difference in the two populations is due to the difference in socio-economic context, or the banality of purchasing counterfeit products or some other factor. More research would be needed to establish specifically why there is this particular difference.

Another important contribution made by this research is the fact that for Pakistani consumers, the ethical factor is not strong when it comes to intended purchasing behaviour and this warrants additional research. Most of the time, counterfeits make the customer blind to their personal and professional morals and ethical reservations. In a developed country (the UK), a small number of customers had purchased counterfeit products knowingly, compared to Pakistan, because of the potential consequences. Thus consumers of different cultures exhibit different attitudes when purchasing counterfeit products and the consumers of the developing country seem to ignore relevant ethical issues, while customers of a developed economy consider these ethical issues relevant. This is a striking finding and warrants further research.

Interestingly, status and price had the same influence on both populations’ purchasing intentions. Considering however, how much more the Pakistani population engages in counterfeit purchasing, it may make sense to eliminate the two factors that are specifically relevant to them (perceived quality and ethics) and thus work on the softer side of brand regulation, i.e. negative advertising of counterfeit products, especially in terms of lower quality and as a crime, may help more in countries like Pakistan than more stringent regulation.

The findings of the study can assist companies to take positive measures towards reducing the volume of counterfeit products sold and promote the purchase of authentic products. The foremost reasons why individuals show inclination towards counterfeit products are: 1) Higher prices of original products; 2) Resemblance in product features of original and counterfeited products; 3) Easy availability of counterfeited products in markets; and 4) Affordable or low price of counterfeit products.

The likelihood of an individual being involved in the purchase of counterfeit products increases with lower, price thus by keeping the economic condition of the country in mind, if manufacturers of original products reduce prices for certain product lines they can increase the likelihood of customers being involved in the purchase of original products. In fact, one can argue that in the 
absence of cheaper lines for branded products the customers of counterfeit products in a country like Pakistan were never potential customers of luxury branded products.

Similarly, companies should also concentrate more on distinguishing their products compared to counterfeits with the intention of making it easier for individuals to identify the difference between the counterfeited and original products. By running awareness campaigns to educate consumers about the negative consequences resulting from the consumption of counterfeit products and also by highlighting the aspects of quality, companies can restrict individuals from the purchase of counterfeit product. Such campaigns will be an effective tool against illegal businesses. As suggested by Grossman and Shapiro (1988), there are two categories of counterfeits, i.e. deceptive and non-deceptive counterfeiting, policymakers in developing countries should also develop anticounterfeiting campaigns directed at those consumers who are unknowingly purchasing counterfeit products by highlighting the ethical issues related to consumption of counterfeit products.

The study was limited to a specific product category, i.e. luxury products. Though considering a single product category for the study, this allows possible control over confounding effects that may be exerted by multiple categories; however, individuals' responses may vary depending on the category of product, and selecting a single product category may possibly restrict the potential generalizability from the basis of the findings of the study. In future, research should therefore expand this study in other product categories, such as low involvement products (e.g. shampoos). 


\section{References}

Abid, M. \& Abbasi, M. (2014). Antecedents and outcomes of consumer buying attitude; the case of pakistani counterfeit market. Indian J. Sci. Res, 8 (1), 165-176.

Ahmad, M. (2009). Business ethics in islam, International Institute of Islamic Thought (IIIT).

Ahmad, N., Yousuf, M., Shabeer, K. \& Imran, M. (2014). A comprehensive model on consumer's purchase intention towards counterfeit mobiles in pakistan. Journal of Applied Science Research, 4 (5), 131-140.

Ajzen, I. (1991). The theory of planned behavior. Organizational behavior and human decision processes, 50 (2), 179-211.

Alcock, L., Chen, P., Ch’ng, H. M. \& Hodson, S. (2003). Counterfeiting: Tricks and trends. Journal of Brand Management, 11 (2), 133-136.

Alfadl, A. A., Ibrahim, M. I. M. \& Hassali, M. a. A. (2014). How ethics influence intentions to buy counterfeit drugs: Perceptions of policymakers, community pharmacists and consumers in sudan. Journal of Pharmaceutical Health Services Research, 5 (3), 181186.

Ali, A. J. (2011). 2 islamic ethics and marketing. Handbook of Islamic marketing, 17.

Ali, A. J. \& Al-Aali, A. (2015). Marketing and ethics: What islamic ethics have contributed and the challenges ahead. Journal of Business Ethics, 129 (4), 833-845.

Ali, M. \& Jamal, M. F. (2011). Exploring relationship among factors of willingness of consumer toward counterfeit products in pakistan. Internationa Journal of Management \& Organizational Studies, 2 (1), 66-72.

Ang, S., Sim Cheng, P., Lim, E. A. \& Kuan Tambyah, S. (2001). Spot the difference: Consumer responses towards counterfeits. Journal of consumer marketing, 18 (3), 219-235.

Babin, B. J. \& Babin, L. (2001). Seeking something different? A model of schema typicality, consumer affect, purchase intentions and perceived shopping value. Journal of Business Research, 54 (2), 89-96.

Babu, M. G., Vani, G. \& Panchanatham, N. (2011). Consumer buying behaviour the controllabes \& uncontrollables. International Journal of Ecxclusive Management Research, 1 (1), 112.

Barnett, J. M. (2005). Shopping for gucci on canal street: Reflections on status consumption, intellectual property. Virginia Law Review, 1381-1423.

Bian \& Moutinho (2011). The role of brand image, product involvement, and knowledge in explaining consumer purchase behaviour of counterfeits: Direct and indirect effects. European Journal of Marketing, 45 (1/2), 191-216.

Bian, X. \& Veloutsou, C. (2007). Consumers' attitudes regarding non-deceptive counterfeit brands in the uk and china. Journal of Brand Management, 14 (3), 211-222.

Bian, X., Haque, S. \& Smith, A. (2015). Social power, product conspicuousness, and the demand for luxury brand counterfeit products. British Journal of Social Psychology, 54 (1), 3754.

Bloch, P. H., Bush, R. F. \& Campbell, L. (1993). Consumer “accomplices” in product counterfeiting: A demand side investigation. Journal of consumer marketing, 10 (4), 2736.

Boomsma, A. (1985). Nonconvergence, improper solutions, and starting values in lisrel maximum likelihood estimation. Psychometrika, 50 (2), 229-242.

Browne, M. W., Cudeck, R., Bollen, K. A. \& Long, J. S. (1993). Alternative ways of assessing model fit. Sage focus editions, 154 136-136. 
Budiman, S. (2012). Analysis of consumer attitudes to purchase intentions of counterfeiting bag product in indonesia. International Journal of Management, Economics and Social Sciences, 1 (1), 1-12.

Carmins, E. \& Zeller, R. A. (1979). Reliability and validity assessment. Beverly hills. CA: Sage Publications.

Carpenter, J. M. \& Edwards, K. E. (2013). Us consumer attitudes toward counterfeit fashion products. Journal of Textile \& Apparel Technology \& Management (JTATM), 8 (1).

Castaño, R. \& Eugenia Perez, M. (2014). A matter of love: Consumers’ relationships with original brands and their counterfeits. Journal of consumer marketing, 31 (6/7), 475-482.

Chaudary, M. W. T., Ahmed, F., Gill, M. S. \& Rizwan, M. (2014). The determinants of purchase intention of consumers towards counterfeit shoes in pakistan. Journal of Public

Administration and Governance, 4 (3), Pages 20-38.

Chaudhry, P., Cordellb, V. \& Zimmermanc, A. (2005). Modelling anti-counterfeiting strategies in response to protecting intellectual property rights in a global environment. The Marketing Review, 5 (1), 59-72.

Chaudhry, P. E. \& Stumpf, S. A. (2011). Consumer complicity with counterfeit products. Journal of consumer marketing, 28 (2), 139-151.

Chaudhuri, H. R. \& Majumdar, S. (2006). Of diamonds and desires: Understanding conspicuous consumption from a contemporary marketing perspective. Academy of Marketing Science Review, 11 (2/3), 2-18.

Cheek, W. K. \& Easterling, C. R. (2008). Fashion counterfeiting: Consumer behavior issues. Journal of Family and Consumer Sciences, 100 (4), 40-48.

Cheung, W.-L. \& Prendergast, G. (2006). Buyers' perceptions of pirated products in china. Marketing Intelligence \& Planning, 24 (5), 446-462.

Chuchinprakarn, S. (2003). Consumption of counterfeit goods in thailand: Who are the patrons. European advances in consumer research, 6 48-53.

Churchill, G. A. (1979). A paradigm for developing better measures of marketing constructs. Journal of Marketing Research, 64-73.

Clark, M. S. \& Mills, J. (1979). Interpersonal attraction in exchange and communal relationships. Journal of personality and social psychology, 37 (1), 12.

Devellis, R. F. (2003). Scale development: Theory and applications, United States of America SAGE Publication Ltd.

Dubinsky, A. J., Nataraajan, R. \& Huang, W.-Y. (2005). Consumers' moral philosophies: Identifying the idealist and the relativist. Journal of Business Research, 58 (12), 16901701.

Eastman, J. K., Goldsmith, R. E. \& Flynn, L. R. (1999). Status consumption in consumer behavior: Scale development and validation. Journal of Marketing Theory and Practice, 41-52.

Eastman, J. K. \& Eastman, K. L. (2011). Perceptions of status consumption and the economy. Journal of Business \& Economics Research (JBER), 9 (7), 9-20.

Eisend, M. \& Schuchert, P. (2006). Explaining counterfeit purchases: A review and preview. Academy of Marketing Science Review, 12 (6), 1-25.

Ergin, E. A. (2010). The rise in the sales of counterfeit brands: The case of turkish consumers. African Journal of Business Management, 4 (10), 2181-2186.

Forsyth, D. R. (1980). A taxonomy of ethical ideologies. Journal of personality and social psychology, 39 (1), 175. 
Franke, R. H., Hofstede, G. \& Bond, M. H. (1991). Cultural roots of economic performance: A research notea. Strategic Management Journal, 12 (S1), 165-173.

Furnham, A. \& Valgeirsson, H. (2007). The effect of life values and materialism on buying counterfeit products. The Journal of Socio-Economics, 36 (5), 677-685.

Gajjar, D. (2013). Factors affecting consumer behavior. International Journal of Research in Humanities and Social Sciences, 1 (2), 10-15.

Gary, A. (2017). The world's biggest economies in 2017 [Online]. World Economic Forum. Available: https://www.weforum.org/agenda/2017/03/worlds-biggest-economies-in2017/ [Accessed 05 July 2017].

Gentry, J. W., Putrevu, S. \& Shultz, C. J. (2006). The effects of counterfeiting on consumer search. Journal of Consumer Behaviour, 5 (3), 245-256.

Gino, F., Norton, M. I. \& Ariely, D. (2010). The counterfeit self the deceptive costs of faking it. Psychological Science.

Grossman, G. M. \& Shapiro, C. (1988). Foreign counterfeiting of status goods. The Quarterly Journal of Economics, 79-100.

Ha, N. M. \& Tam, H. L. (2015). Attitudes and purchase intention towards counterfeiting luxurious fashion products in vietnam. International Journal of Economics and Finance, 7 (11), 207.

Ha, S. \& Lennon, S. J. (2006). Purchase intent for fashion counterfeit products: Ethical ideologies, ethical judgments, and perceived risks. Clothing and Textiles Research Journal, 24 (4), 297-315.

Hair, William C. Black, Barry J. Babin \& Anderson, R. E. (2009). Multivariate data analysis, Upper Saddle River NJ., Prentice Hall.

Hair, J. F., Ringle, C. M. \& Sarstedt, M. (2011). Pls-sem: Indeed a silver bullet. Journal of Marketing Theory and Practice, 19 (2), 139-152.

Hamelin, N., Nwankwo, S. \& Hadouchi, R. (2013). 'Faking brands': Consumer responses to counterfeiting. Journal of Consumer Behaviour, 12 (3), 159-170.

Hart, S., Hoe, L. \& Hogg, G. (2004). Faking it: Counterfeiting and consumer contradictions. European Advances in Consumer Behaviour, 6 60-67.

Hieke, S. (2010). Effects of counterfeits on the image of luxury brands: An empirical study from the customer perspective. Journal of Brand Management, 18 (2), 159-173.

Hilton, B., Choi, C. J. \& Chen, S. (2004). The ethics of counterfeiting in the fashion industry: Quality, credence and profit issues. Journal of Business Ethics, 55 (4), 343-352.

Hopkins, D., Kontnik, L. \& Turnage, M. (2003). Counterfeiting exposed: Protecting your brand and customers., New Jersey, John Wiley \& Sons,.

Hu, L. T. \& Bentler, P. M. (1999). Cutoff criteria for fit indexes in covariance structure analysis: Conventional criteria versus new alternatives. Structural equation modeling: $a$ multidisciplinary journal, 6 (1), 1-55.

Huang, J.-H., Lee, B. C. \& Hsun Ho, S. (2004). Consumer attitude toward gray market goods. International Marketing Review, 21 (6), 598-614.

Husted, B. W. (2000). The impact of national culture on software piracy. Journal of Business Ethics, 26 (3), 197-211.

Ian, P., Teah, M. \& Lee, A. (2009). Targeting buyers of counterfeits of luxury brands: A study on attitudes of singaporean consumers. Journal of Targeting, Measurement and Analysis for Marketing, 17 (1), 3-15. 
Jacobs, L., Samli, A. C. \& Jedlik, T. (2001). The nightmare of international product piracy: Exploring defensive strategies. Industrial Marketing Management, 30 (6), 499-509.

Jang, S. S. \& Namkung, Y. (2009). Perceived quality, emotions, and behavioral intentions: Application of an extended mehrabian-russell model to restaurants. Journal of Business Research, 62 (4), 451-460.

Juggessur, J. (2009). Is fashion promoting counterfeit brands. Journal of Brand Management, (16), $383-394$.

Kacen, J. J. \& Lee, J. A. (2002). The influence of culture on consumer impulsive buying behavior. Journal of Consumer Psychology, 2 (12), 163-176.

Kapferer, J.-N. \& Michaut, A. (2014). Luxury counterfeit purchasing: The collateral effect of luxury brands’ trading down policy. Journal of Brand Strategy, 3 (1), 59-70.

Kemal, M. A. (2006). Is inflation in pakistan a monetary phenomenon? The Pakistan Development Review, 213-220.

Kempen, L. V. (2003). Fooling the eye of the beholder:. Journal of International Development, 15 157-177.

Kline, R. B. (2010). Principles and practice of structural equation modeling, Guilford publications.

Kotler, P., Saliba, S. \& Wrenn, B. (1991). Marketing management: Analysis, planning, and control: Instructor's manual, USA, Prentice-Hall.

Lau, C. M. \& Roopnarain, K. (2014). The effects of nonfinancial and financial measures on employee motivation to participate in target setting. The British accounting review, 46 (3), 228-247.

Lee, S. H. \& Workman, J. E. (2011). Attitudes toward counterfeit purchases and ethical beliefs among korean and american university students. Family and Consumer Sciences Research Journal, 39 (3), 289-305.

Li, T. \& Seaton, B. (2015). Emerging consumer orientation, ethical perceptions, and purchase intention in the counterfeit smartphone market in china. Journal of International Consumer Marketing, 27 (1), 27-53.

Maines, D. R. (1989). Rediscovering the social group: A self-categorization theory. John c. Turner michael a. Hogg penelope j. Oakes stephen d. Reicher margaret s. Wetherell.

Maldonado, C. (2005). Attitudes toward counterfeit products an ethical perspective. Journal of Legal, Ethical and Regulatory, 8 (2), 105-117.

Matos, Trindade Ituassu, C. \& Vargas Rossi, C. A. (2007). Consumer attitudes toward counterfeits: A review and extension. Journal of Consumer Marketing, 24 (1), 36-47.

Michaelidou, N. \& Christodoulides, G. (2011). Antecedents of attitude and intention towards counterfeit symbolic and experiential products. Journal of Marketing Management, 27 (9-10), 976-991.

Mujtaba, B. G., Sikander, A., Akhtar, N. \& Afza, T. (2012). Business ethics of pakistanis in islamabad and lahore: Do age, gender and data collection processes make a difference? International Journal of Learning and Development, 2 (3), 325-341.

Nia, A., Lynne Zaichkowsky \& Judith (2000). Do counterfeits devalue the ownership of luxury brands? Journal of Product \& Brand Management, 9 (7), 485-497.

Norum, P. S. \& Cuno, A. (2011). Analysis of the demand for counterfeit goods. Journal of Fashion Marketing and Management: An International Journal, 15 (1), 27-40.

Nueno, J. L. \& Quelch, J. A. (1998). The mass marketing of luxury. Business Horizons, 41 (6), 61-68. 
Nunnally, J. C. (1978). Psychometric theory., New York: MacGraw-Hill.

Nunnally, J. C. \& Bernstein, I. (1994). Psychological theory, New York: McGraw-Hill.

Park, H.-J., Rabolt, N. J. \& Sook Jeon, K. (2008). Purchasing global luxury brands among young korean consumers. Journal of Fashion Marketing and Management: An International Journal, 12 (2), 244-259.

Penz, E. \& Stottinger, B. (2005). Forget the" real" thing-take the copy! An explanatory model for the volitional purchase of counterfeit products. Advances in consumer research, 32568.

Penz, E., Schlegelmilch, B. B. \& Stöttinger, B. (2008). Voluntary purchase of counterfeit products: Empirical evidence from four countries. Journal of International Consumer Marketing, 21 (1), 67-84.

Perez, M. E., Castaño, R. \& Quintanilla, C. (2010). Constructing identity through the consumption of counterfeit luxury goods. Qualitative Market Research: An International Journal, 13 (3), 219-235.

Phau, Ian Sequeira, Marishka Dix \& Steve (2009). Consumers' willingness to knowingly purchase counterfeit products. Direct Marketing: An International Journal, 3 (4), 262281.

Prendergast, G., Hing Chuen, L. \& Phau, I. (2002). Understanding consumer demand for nondeceptive pirated brands. Marketing Intelligence \& Planning, 20 (7), 405-416.

Rani, P. (2014). Factors influencing consumer behaviour. International Journal of Current Research and Academic Review, 2 (9), 52-61.

Reid, F. (1987). Rediscovering the social group: A self-categorization theory. British Journal of Social Psychology, 26 (4), 347-348.

Riquelme, H. E., Mahdi Sayed Abbas, E. \& Rios, R. E. (2012). Intention to purchase fake products in an islamic country. Education, Business and Society: Contemporary Middle Eastern Issues, 5 (1), 6-22.

Rizwan, M., Bukhari, S. R., Ilyas, T., Ain, H. Q. U. \& Gulzar, H. (2010). Purchase intention towards counterfeit product. international Journal of Ressearch in Commerce, IT \& Mangement, 3 (3), 152-158.

Rizwan, M., Jamal, M. N., Zareen, K. G., Khan, A., Farhat, B. \& Khan, R. (2013). The determinants of purchase intention towards counterfeit mobile phones in pakistan. Asian Journal of Empirical Research, 3 (2), 220-236.

Rutter, J. \& Bryce, J. (2008). The consumption of counterfeit goodshere be pirates?'. Sociology, 42 (6), 1146-1164.

Sagar, M., Khandelwal, R., Mittal, A. \& Singh, D. (2011). Ethical positioning index an innovative tool for differential brand positioning. Corporate Communications: An, 16 124-138.

Shang, R.-A., Chen, Y.-C. \& Chen, P.-C. (2008). Ethical decisions about sharing music files in the p2p environment. Journal of Business Ethics, 80 (2), 349-365.

Staake, T., Thiesse, F. \& Fleisch, E. (2009). The emergence of counterfeit trade: A literature review. European Journal of Marketing, 43 (3/4), 320-349.

Staake, T., Thiesse, F. \& Fleisch, E. (2012). Business strategies in the counterfeit market. Journal of Business Research, 65 (5), 658-665.

Tom, G., Garibaldi, B., Zeng, Y. \& Pilcher, J. (1998). Consumer demand for counterfeit goods. Psychology \& Marketing, 15 (5), 405-421.

Triandis, H. C. (2001). Individualism-collectivism and personality. Journal of personality, 69 (6), 907-924. 
Van Kempen, L. (2003). Fooling the eye of the beholder: Deceptive status signalling among the poor in developing countries. Journal of International Development, 15 (2), 157-177.

Vandenbosch, B. \& Higgins, C. (1996). Information acquisition and mental models: An investigation into the relationship between behaviour and learning. Information Systems Research, 7 (2), 198-214.

Vida, I. (2007). Determinants of consumer willingness to purchase non-deceptive counterfeit products. Managing global transitions, 5 (3), 253-270.

Vigneron, F. \& Johnson, L. W. (2004). Measuring perceptions of brand luxury. Journal of Brand Management, 11 (6), 484-506.

Vitell, S. J. (2003). Consumer ethics research: Review, synthesis and suggestions for the future. Journal of Business Ethics, 43 (1-2), 33-47.

Wani, T. A. (2013). Buying behaviour-an islamic perspective an analysis of an ideal muslim buying behaviour. The Journal of Commerce, 5 (2), 10.

Wee, C.-H., Ta, S.-J. \& Cheok, K.-H. (1995). Non-price determinants of intention to purchase counterfeit goods: An exploratory study. International Marketing Review, 12 (6), 19-46.

Weston, R. \& Gore, P. A. (2006). A brief guide to structural equation modeling. The Counseling Psychologist, 34 (5), 719-751.

Wilcox, K., Kim, H. M. \& Sen, S. (2009). Why do consumers buy counterfeit luxury brands? Journal of Marketing Research, 46 (2), 247-259.

Wolf, E. J., Harrington, K. M., Clark, S. L. \& Miller, M. W. (2013). Sample size requirements for structural equation models an evaluation of power, bias, and solution propriety. Educational and Psychological Measurement, 73 (6), 913-934.

Yao, J.-T. (2005). Counterfeiting and an optimal monitoring policy. European Journal of Law and Economics, 19 (1), 95-114.

Yao, J.-T. (2015). The impact of counterfeit-purchase penalties on anti-counterfeiting under deceptive counterfeiting. Journal of Economics and Business, 80 51-61.

Yoo, B. \& Lee, S.-H. (2009). Buy genuine luxury fashion products or counterfeits. Advances in Consumer Research, 36 280-286.

Zeithaml, V. A., Berry, L. L. \& Parasuraman, A. (1996). The behavioral consequences of service quality. The Journal of Marketing, 31-46.

Zhan, L., Sharma, P., Chan, R. Y., Johnston, W. \& Johnston, W. (2015). Using spotlight effect to curb counterfeit consumption-an experimental investigation. Marketing Intelligence \& Planning, 33 (4). 